\title{
DESCENTRALIZAÇÃO E AUTONOMIA MUNICIPAL: UMA ANÁLISE DAS TRANSFORMAÇÕES INSTITUCIONAIS NO FEDERALISMO BRASILEIRO ${ }^{1}$
}

\author{
DECENTRALIZATION AND MUNICIPAL AUTONOMY: AN \\ ANALYSIS OF INSTITUCIONAL CHANGES IN THE BRAZILIAN \\ FEDERALISM
}

\begin{abstract}
Angela Moulin Simões Penalva Santos
Pós-Doutora (FAU/USP), Professora Associada da UERJ e Pesquisadora do CNPQ angelapenalva@ terra.com.br
\end{abstract}

\section{Resumo:}

O objetivo deste artigo é analisar o contexto histórico-institucional em que se situa a autonomia dos governos municipais no âmbito do federalismo brasileiro. A constituição de1988 tornou o Município “ente federativo" dotado de autonomia política, legislativa,administrativa e financeira. $\mathrm{O}$ novo desenho institucional, no entanto, suscitou reações quecolocaram em xeque aquela autonomia, em particular a financeira. Para avaliar tais reaçõesforam levantadas as Emendas à Constituição que afetaram a autonomia municipal ao longodos últimos 24 anos em que a atual Constituição está em vigor. Dados relativos a algunsindicadores de finanças municipais foram apresentados para situar o impacto das reformasconstitucionais. A análise dos dados sugere que os anos 1990 foram marcados por um ataqueà autonomia financeira dos Municípios, considerados entes federativos pouco comprometidoscom o ajuste fiscal em contexto de crise econômica. Na década seguinte, avançou acooperação interfederativa, inclusive com aumento das transferências governamentais para osMunicípios. Resta, contudo, resolver problemas decorrentes da estrutura federativa tripartite,marcado por forte heterogeneidade entre os municípios brasileiros.

Palavras chave: Município. Autonomia financeira. Reformas constitucionais. Finanças municipais. Federação brasileira.

\footnotetext{
Abstract:

${ }^{1}$ Uma versão deste artigo foi publicada na Revista Paranaense de Desenvolvimento, Curibita, n. 120, jan/jun. 2011 sob o título "Autonomia Municipal no Contexto Federativo Brasileiro".

Geo UERJ - Ano 14, no. 23,v. 2, $2^{\circ}$ semestre de 2012 p. 825-852

ISSN: 1415-7543 E-ISSN: 1981-9021

http://www.e-publicacoes.uerj.br/index.php/geouerj
} 
The purpose of this article is to analyze the historical and institutional context in which the autonomy of municipal governments is situated in the Brazilian federative sphere. The 1988's Brazilian Federal Constitution treats the municipality as a "federative entity" with political, legislative, administrative, and financial autonomy. However, the new institutional design provoked reactions that jeopardized such autonomy, especially the financial. In order to evaluate such reactions, the Amendments to the Constitution that somehow affected the municipal autonomy over the last 24 years in which the current Constitution is in force, were raised. Data on some municipal financial indicators were presented to situate the impacts of the constitutional reforms. The data analysis suggests that the 1990s were marked by an attack to the financial autonomy of the municipalities, which were considered federative entities somewhat committed to the fiscal adjustment in the economic crisis background. During the following decade, the interfederative cooperation increased, even with the expansion of governmental transfers to the Municipalities. However, problems arising from tripartite federal structures, marked by a strong heterogeneity between Brazilian municipalities, still have to be solved.

Keywords: Municipality. Financial autonomy. Constitutional reforms. Municipal finances. BrazilianFederation.

\section{Introdução}

O objetivo deste artigo é analisar o contexto histórico-institucional em que se situa aautonomia dos governos municipais no âmbito do federalismo brasileiro.

A constituição de 1988 tornou o Município "ente federativo" dotado de autonomiapolítica, legislativa, administrativa e financeira. Ademais, tornou o Município o enteresponsável pela política urbana, num contexto marcado pela ampliação dos direitos sociais epela execução descentralizada das políticas sociais, ampliando as atribuições dos governosmunicipais.

O novo desenho institucional, no entanto, suscitou reações que colocaram em xequeaquela autonomia, em particular a financeira.

Num primeiro momento (1989-1995), a autonomia municipal foi experimentada pormeio da elevação das receitas, especialmente as oriundas das transferênciasintergovernamentais, o que contribuiu para fortalecer a autonomia política frente aos estados eà União.

Uma vez estabilizadas as receitas de transferências intergovernamentais, uma novaetapa se seguiu, ao longo dos dois mandatos do presidente Fernando Henrique 
Cardoso (1995-2002). Nesse período, a União passou a recuperar sua participação na partilha federativa daarrecadação das receitas públicas por meio da elevação de tributos não partilháveis com osdemais entes da Federação. O aumento das receitas municipais passou a depender daarrecadação própria, mas em um contexto de crise econômica, o que limitava suaspossibilidades de elevação de receitas.Apesar disso, com a descentralização das políticassociais, os compromissos municipais cresceram.

A limitação da autonomia financeira municipal, conjugada às maioresresponsabilidades assumidas pelas prefeituras, levou à reação dos municípios, que seorganizaram e formaram entidades para defender seus interesses, como a ConfederaçãoNacional dos Municípios $(\mathrm{CNM})^{2}$.

Ao longo dos dois mandatos do presidente Luis Inácio Lula da Silva (20032010), adisputa federativa entrou numa terceira etapa, durante a qual ocorreu a continuação dofortalecimento institucional da União, responsável pela formulação das diversas políticassociais, porém atendendo parcialmente ao interesse dos municípios ao elevar o valor das transferências intergovernamentais.

Essa etapa foi marcada pelo que passou a ser definidocomo "coordenação federativa", situação em que a União passou a ter maior controle sobreo desenho institucional das políticas sociais, mas respeitando a autonomia política deestados e municípios, que não poderiam ser obrigados a aderir às políticas formuladas pelaUnião.Apesar disso, os demais entes federativos aderiram às políticas como forma dereceber fundos vinculados àquelas políticas.

Este artigo está estruturado em quatro seções, além desta introdução.Na segunda,apresentamos elementos que permitam compreender o contexto no qual o Município foielevado à condição de "ente federativo" quando o federalismo brasileiro tornou-se tripartite,constituído de União, estados e municípios. Na terceira seção, o objetivo é situar asreformas constitucionais que afetaram o pacto federativo instituído em 1988, quando entrouem vigor a atual Constituição. A quarta seção é dedicada à análise de dados sobre asfinanças municipais, visando situar o impacto das mudanças institucionais sobre aautonomia financeira dos municípios. $\mathrm{Na}$ quinta seção,

\footnotetext{
${ }^{2}$ Seu endereço eletrônico oficial é www.cnm.org.br. 
apresentamos algumas reflexõessobre a situação atual do Município na estrutura federativa brasileira.

\section{O Município torna-se ente federativo como resposta à crise urbana}

A elevação do Município à condição de ente federativo tem sido analisada sobdiferentes prismas. Na perspectiva política, tratava-se de um processo de redemocratizaçãodas estruturas de poder, de modo a transferir até a esfera local de governo as políticas sociais,onde elas poderiam ser mais bem submetidas ao controle social (ARRETCHE, 2000;HOLFMEISTER, 2001; FLEURY, 2006).

$\mathrm{Na}$ perspectiva dominante entre economistas, talfortalecimento dos municípios alimentou aingovernabilidade, devido à perda de receitas daesfera federal de poder; à incapacidade técnica dos municípios para assumir as novasresponsabilidades de políticas, além dos problemas derivados da insuficiência de escala que amaioria dos municípios apresenta no que tange a várias políticas públicas (AFFONSO;SILVA, 1995; MENDES, 2004; AFFONSO, 2004; RESENDE, 2007). Desde então, temprevalecido esta segunda perspectiva, de tal sorte que, ao longo dos últimos 24 anos,passamos da defesa das virtudes da descentralização ao processo de recentralização do poderpúblico.

No entanto, não houve recentralização nas políticas cuja execução foratransferida para os municípios. Ao contrário, houve obrigatoriedade crescente de os municípiosassumirem parte do financiamento das políticas públicas, em particular no setor da educaçãofundamental e na saúde. Na verdade, o Município tornou-se o instrumento de redistribuiçãoespacial de condições mínimas de direitos de cidadania; nesse sentido, manteve-se o espírito dopacto federativo de 1988.

Duas ideias são centrais para compreender o significado, o propósito e osucesso na formação de uma federação: a de autonomia e a de participação. Em relação àprimeira, a Constituição de 1988 assegurou ao Município quatro capacidades: a) deauto-organização,por meio de uma lei orgânica elaborada e promulgada por sua Câmara deVereadores, sem interferência de qualquer espécie de Legislativo Estadual ou Federal; b) deautogoverno, exercida pelo prefeito e vereadores eleitos pelo voto direto e secreto; c) deautolegislação sobre assuntos de interesse local e sobre outros, de forma 
suplementar econcorrente; e d) de autoadministração, para arrecadar os tributos de sua competência, aplicarsuas receitas e prestar serviços públicos à comunidade local.

Entretanto, em relação à ideia central da participação, a situação do entemunicipal é bem outra. Primeiro, é necessário esclarecer que tal participação é tomada nosentido de valoração da vontade política de todos os entes federados na construção dasoberania da Federação, mas também no sentido de cooperação e ampliação da autonomiaentre tais entes, autonomia obtida mediante uma repartição constitucional de competênciasque leve em conta a mesma vontade de todos os entes na sua formação.

Na verdade, arepartição de competências na Constituição de 1988, embora tenha sofrido grande influênciade associações e entidades que defendiam a causamunicipalista, não foi determinada levandoem conta a participação política dos municípios, mesmo porque eles inexistiam formalmentepara a Federação até então.

O princípio geral que delineia a repartição de competências entre as entidadescomponentes do Estado Federal é o da "predominância do interesse", que se manifesta nasafirmações de que à União caberão as matérias de "interesse geral"; aos estados, as de"predominante interesse regional"; e, aos municípios, aqueles "assuntos de interesse local".

Com base nesse princípio geral, a Constituição estabelece as regras para a divisão dascompetências administrativas e legislativas, definindo as reservas de campos específicos.Concede à Uniãocompetências exclusivas e comuns, conforme os poderes enumerados nosArtigos 21 e 22; destina aos estados os poderes remanescentes previstos no Artigo 25,parágrafo 1; aos municípios, transfere os poderes enumerados no Artigo 30.

As responsabilidades de competência dos municípios que estão explícitas naConstituição Federal abrangem: a) organizar e prestar, diretamente ou sob regime deconcessão ou permissão, os serviços de interesse local, incluído transporte coletivo, que temcaráter essencial; b) manter e prestar, com a cooperação técnica e financeira da União e dosestados, os programas de Educação Infantil e de Ensino Fundamental; c) os serviços deatendimento à saúde; d) promover, no que couber, adequado ordenamento territorial,mediante planejamento e controle do uso, do parcelamento e da ocupação do solo urbano; e)promover a proteção do patrimônio histórico-cultural local. 
Muito mais numerosas são as responsabilidades compartilhadas com osâmbitos federal e estadual de governo, que incluem: a) cuidar da saúde e assistência pública, da proteção e garantia das pessoas portadoras de deficiência; b) proteger os documentos, asobras e outros bens de valor histórico, artístico e cultural, os monumentos, as paisagensnaturais notáveis e os sítios arqueológicos; c) proporcionar os meios de acesso à cultura, àeducação e à ciência; d) proteger o meio ambiente e combater a poluição em qualquer de suasformas; e) preservar as florestas, a fauna e a flora; f) fomentar a produção agropecuária eorganizar o abastecimento alimentar; g) promover programas de construção de moradias emelhoria das condições habitacionais; h) promover programas de saneamento básico; i)combater as causas da pobreza e os fatores de marginalização, promovendo a integraçãosocial dos setores desfavorecidos; j) registrar, acompanhar e fiscalizar as concessões dedireitos de pesquisa e exploração de recursos hídricos e minerais em seus territórios; e l)estabelecer e implantar política de educação para a segurança do trânsito.

Os constituintes de 1988 acreditavam na idéia da cooperação entre os entesfederativos, mas definiram que a descentralização deveria reger a distribuição decompetências administrativas, sustentada no princípio da subsidiariedade, tal comoprevistona Constituição alemã. Esse princípio estabelece que as esfera estadual e federal devemprevalecer sobre os governos municipais somente quando esses não estiverem aptos aexecutar eficientemente as políticas governamentais.

A subsidiariedade escalona asatribuições em função da complexidade do atendimento dos interesses da sociedade.No entanto, ao criar uma terceira esfera de poder em um contexto de enormeheterogeneidade entre os Municípios, o resultado foi que aqueles poucos de maior pesodemográfico e econômico puderam beneficiar-se muito mais da sua condição de entefederativo do que a grande maioria. Como resultado, a estrutura federativa brasileira assumiuuma feição mais competitiva entre seus entes do que aquela cooperação pretendida.

Além disso, o sucesso da descentralização enfrentou também o desafio dasdemandas por ampliação e efetividade dos direitos de cidadania, bem como a luta por maiorautonomia financeira dos municípios, num contexto em que a União reagia à perda de receitase passaria a impor uma recentralização das finanças públicas ${ }^{3}$. É nesse

\footnotetext{
${ }^{3} \mathrm{~A}$ estrutura das receitas municipais será abordada na quarta seção do artigo. 
ambiente que prosperaa crítica a respeito do papel do Município no federalismo brasileiro.

\section{O federalismo como ele é...}

O federalismo em vigor é muito diferente daquele pactuado pelos constituintes de1988. O Município segue sendo ente federativo, mas a autonomia conquistada vem sendolimitada por reformas constitucionais que afetam a capacidade dos governos municipais deprotagonizar políticas públicas.

A Constituição de 1988 previu a realização de uma revisão constitucional em1993, um momento conturbado da vida política brasileira, quando estiveram muitoenfraquecidos os Poderes Executivo e o Legislativo ${ }^{4}$. Assim, quase todas as reformasconstitucionais realizadas tiveram que aguardar a posse de um novo presidente eleito,

politicamente fortalecido e capaz de realizar um importante programa de reformas doEstado.

Ao longo destes 24 anos de vigência da Constituição, foram editadas 71 emendasconstitucionais (EC), das quais 26 afetam a autonomia municipal ${ }^{5}$. Durante os dois mandatosdo presidente Fernando Henrique Cardoso (1995/2002), foram aprovadas 14 emendas, sendoas outras 12 ao longo dos oito anos do governo do presidente Lula (2003/2010).

As emendas constitucionais que tiveram impacto sobre a autonomia municipal podem ser distribuídas entre quatro tipos: i) alteram o sistema tributário; ii) diminuem astransferências aos municípios; iii) criam políticas sociais com participação dosmunicípios noseu financiamento; e iv) afetam a autonomia política municipal.

i)Emendas que alteram o sistema tributário

No grupo das que alteram o sistema tributário, há aquelas que afetampositivamente a autonomia financeira dos municípios e as que afetam negativamente. Noprimeiro caso estão as EC 37, 39, 42, 44 e 55; no segundo, as EC de Revisão 1 e as EC 3, 12,21, 31 e 37. Como se pode perceber, as mudanças que beneficiaram os municípios foram maisrecentes; em contrapartida, aquelas que afetaram

\footnotetext{
${ }^{4}$ Era então presidente da República Itamar Franco, que havia sido eleito vice-presidente e assumira o governo ${ }^{5}$ Estas Emendas Constitucionais estão apresentadas no Anexo. 
negativamente foram mais numerosas e maisantigas; identificam-se com a reação da União ao fortalecimento dos governos locais.

Dentre as EC que podem conduzir à maior autonomia dos municípios, somenteas EC 39, 42, 44 e 55 beneficiam os pequenos municípios, que são a grande maioria dosmunicípios brasileiros $(71 \%$ deles tem população inferior a 20 mil habitantes) e têm sua baseeconômica muito dependente da atividade rural; por isso, pouco se beneficiam da autonomiapara gerir tributos de competência municipal, uma vez que estes incidem sobre atividadesurbanas. À grande maioria desses municípios interessam medidas que resultem em aumentodas transferências (sobretudo o FPM), mesmo que sejam transferências voluntárias, como são os convênios. Aos municípios de maior porte importa ampliar a sua competência tributária.

A EC 37, que previu uma nova lei para definir serviços sobre os quaisincide oISS, pouco ajuda os municípios, exceto aqueles maiores, comimportante atividade econômicade base urbano-industrial. E estes foram beneficiados também com a instituição de umpercentual mínimo de alíquota do ISS (EC 37), de modo a enfrentar a guerra fiscal que osmunicípios de pequeno porte estavam travando mediante o recurso de oferecer menoresalíquotas daquele imposto para atrair a localização de empresas.

A EC 39, editada nos últimos dias do governo Fernando Henrique Cardoso(em 19 de dezembro de 2002), foi a única que, ao longo dos dois mandatos desse presidente, alterou o sistema tributário nacional de modo favorável a todos os municípios, inclusive ospequenos, ao criar a Contribuição para o Custeio da Iluminação Pública (CIDE) nosmunicípios e Distrito Federal.O tributo já havia sido criado, mas como "taxa", a EC mudou anatureza jurídica do tributo para "contribuição", devido a seguidas declarações deinconstitucionalidade pelo Judiciário, uma vez que se tratava de tributo vinculado.

A retomada da reforma tributária no governo Lula trouxe algum alento aosmunicípios. Os ganhos referem-se à participação na arrecadação da CIDE, da ordem de $25 \%$ daquilo que os estados receberem. Ademais, foi permitido que os municípios passassem agerir o ITR e, neste caso, apropriarem-se de toda sua arrecadação, e não apenas dos 50\%,conforme vigorava (EC 42). Outra medida que beneficiou todos os municípios foi o aumentoda parcela da CIDE a ser transferida às esferas infranacionais, passando a ser de $29 \%$ de suaarrecadação (EC 44). Mas a medida de maior impacto 
sobre as finanças dos municípiosbrasileiros, especialmente aqueles de pequeno porte populacional, foi a oaumento em 1 pontopercentual adicional no FPM, determinado pela EC 55.

As alterações no sistema tributário que afetaram negativamente os municípios forameditadas durante os mandatos do presidente Cardoso; referem-se basicamente à criação detributo sobre a movimentação financeira. Inicialmente chamado "Imposto sobreMovimentação Financeira" (EC 3), passou a ser denominado "Contribuição Provisória sobreMovimentação Financeira" (EC 12), sendo prorrogada, a partir de então, em períodosregulares por novas emendas (EC 21, 37), até ser extinto em 2007, quando o Congresso nãoaprovou nova prorrogação do tributo.

Marcado por um contexto de fortes restrições orçamentárias devido ao compromissocom o ajuste fiscal, considerado necessário para consolidar a estabilização monetária, assimcomo para enfrentar a grave crise econômica mundial no biênio 1997/98, o governo Cardosoempreendeu reformas que limitaram a autonomia financeira dos estados e municípios. Os doismandatos do presidente Lula, por outro lado, foram marcados pela retomada do crescimento,o que proporcionou maior folga orçamentária, permitindo a elevação dos gastos públicos;assim, diminuiu apreocupação com a situação fiscal do País, o que resultou em mudança decomportamento físcal da União em relação aos demais entes federativos. Tal mudança estárefletida na natureza distinta dos impactos das reformas constitucionais sobre a autonomia dosmunicípios.

ii) Emendas que diminuem as transferências aos municípios

No segundo grupo incluem-se apenas casos de impactos negativos sobre aautonomia financeira municipal, com a criação (e recriação) do Fundo Social de Emergência,rebatizado de Fundo de Estabilização Fiscal e depois transformado em Desvinculações dasReceitas da União (DRU). Essa evolução ocorreu sucessivamente pela aprovação das EC 10,EC 17, EC 27 e EC 56.

O objetivo dessas mudanças constitucionais foi a União deixar de transferir todos os recursos considerados transferências obrigatórias aos estados e municípios, ficandocom $20 \%$ desse valor para ser alocado por critério estabelecido pelo governo central. A Uniãose defende afirmando que os montantes transferidos efetivamente aos governos estaduais emunicipais não teriam sofrido diminuição. No entanto, ainda que 
isso possa ser verdadeiro,fica patente a perda de autonomia desses entes federativos na alocação de receitas detransferências garantidas pela Constituição da República.

iii) Emendas que criam políticas sociais com participação dos municípios no seu financiamento

O terceiro grupo é constituído pelas EC 14, 26, 29, 31, 53, 59, 64 e 67, com acriação de políticas sociais de educação, moradia, saúde e alimentação, além do fundo depobreza. Em todas elas houve previsão de maior comprometimento dos governos municipais,isto é, aumento de transferência de responsabilidades de políticas públicas desde a União até omunicípio em políticas para as quais se prevê a cooperação entre as três esferas de governo.

A EC 14, de 12 de setembro de 1996, estabeleceu novas e maiores obrigações do Município para com o ensino e autorizou a União a criar o Fundo de Manutenção e Desenvolvimento do Ensino Fundamental e de Valorização do Magistério (Fundef), denatureza contábil. Foi instituído um piso mínimo por estudante matriculado na redemunicipal, sendo a distribuição do FUNDEF realizada de acordo com o tamanho dessa rede.

Na prática, a principal fonte de financiamento do fundo é constituída dos $15 \%$ do ICMS, imposto de competência dos estados, que são obrigados a partilhar $25 \%$ de suaarrecadação com os municípios. A complementação financeira prevista pela União só ocorrequando o total do fundo for insuficiente para gerar o valor mínimo por aluno determinadopara o ano em exercício (valor definido pelo MEC), o que somente ocorreu em quatro estadosnordestinos. Trata-se, assim, de uma política definida na esfera federal e financiada comrecursos estaduais e municipais. Cabe destacar, por fim, que os municípios seguem sendoobrigados a destinar $25 \%$ de sua receita para a função Educação, conforme obrigaçãoconstitucional.

A política para o Ensino Fundamental veio juntar-se a já exitosauniversalização do acesso à saúde básica, instituída na Constituição de 1988 e regulamentadapor lei federal em 1990. Ambas as políticas foram descentralizadas na sua execução, tendo setornado progressivamente mais dependentes do aporte financeiro dos governosmunicipais.Foi o que aconteceu com a entrada em vigor da EC 29. Essa emenda criou uma vinculaçãodas receitas dos governos municipais com a assistência à 
saúde, na proporção de $15 \%$ de suasreceitas correntes. Tal vinculação certamente fere a autonomia municipal em relação àdestinação dada a parte da sua arrecadação tributária própria e das receitas de transferênciasconstitucionais, ambas receitas que a Constituição Federal assegura serem do Município, aoqual cabe administrar segundo o interesse local.

Em contrapartida a tal ingerência na autonomia municipal, a União introduziunessa mesma EC 29 um artigo que tornou constitucional a progressividade na cobrança doIPTU, imposto de competência municipal. Apesar de já previsto na Constituição, o IPTUprogressivo vinha sendo considerado bitributação e, portanto, inconstitucional, o queinviabilizava a sua cobrança pelos municípios. Ademais, o STF confundia a progressividadeprevista no art. 156 (progressividade em razão do valor do imóvel e ter alíquotas diferentes deacordo com a localização e o uso do imóvel) com a do art. 182 (progressividade no tempo),exigindo sempre a aprovação de Plano Diretor para a cobrança progressiva. Por isso, odispositivo que possibilitou a esses entes federativos impor a progressividade na cobrança doIPTU foi apresentado como uma compensação aos municípios, que passaram a ter seuorçamento comprometido com a criada vinculação aos serviços de saúde. Mas, como jámencionado, essa possibilidade inexiste para os municípios de pequeno porte, cuja economiadepende de atividades primárias, só sendo potencialmente beneficiados aqueles de médio e,principalmente, os de grande porte.

Essas emendas constitucionais foram introduzidas ao longo dos oito anos do governo Cardoso, quando foi inaugurada uma nova estratégia de cooperação federativa mediante a indução à adesão dos estados e municípios por meio de recursos de fundos para osquais tornou-se obrigatória a contrapartida do Município. Tal estratégia foi mantida - eampliada - ao longo dos oito anos seguintes, correspondentes aos dois mandatos dopresidente Lula, cujo governo ampliou a abrangência do FUNDEF do Ensino Fundamentalpara atingir todo o Ensino Básico, transformando o FUNDEF em FUNDEB (EC 53). Alémdisso, a EC 59 determinou que os recursos dirigidos à Educação deixariam de estarsubmetidos ao corte de $20 \%$ das DRU.

Outra emenda constitucional que deverá afetar os Municípios é a EC 64, queincluiu a alimentação entre os direitos sociais, o que deverá dar origem a novas políticas 
federais com cooperação federativa induzida pela União, como o que já ocorre no caso dodireito à moradia. Como mencionado antes, a moradia entrou no rol dos direitos sociais em2000, sendo seguida da formulação de um Plano Nacional de Habitação (PNH), dentro doqual foi instituído o Plano Nacional de Habitação de Interesse Social (PNHIS). Em 2009, foi criado o Programa Minha Casa Minha Vida (PMCMV) como política visando darefetividade ao PNHIS. O PMCMV está estruturado com base numa rede federativa vertical,com cooperação voluntária dos municípios, que, entretanto, não deixaram de aderir - eassumir mais compromissos financeiros com a dotação de infraestrutura urbanística nosprojetos de construções de interesse social -, o que os torna elegíveis para receber osrecursos disponibilizados pelo programa.

Por fim, cabe mencionar a EC 67, que prorrogou por prazo indeterminado oFundo de Combate e Erradicação da Pobreza. Significa dizer que o Município continuaráperdendo parte de recursos que lhe seriam transferidos com alocação livre, mantendo aprerrogativa da União, que segue definindo a agenda das políticas sociais. Estas, nunca édemais lembrar, continuam sendo executadas pelos governos municipais, que inclusiveassumem parte de seu financiamento.

iv) Emendas que afetam a autonomia política municipal

Finalmente, o quarto grupo é constituído das EC que afetaram a autonomia política dos municípios, casos das EC 15, 19, 25, 57 e 58. As três primeiras foram editadasdurante o governo Cardoso. As emendas 19 e 25 instituíram limites à autonomiaadministrativa dos municípios (e de toda a administração pública) mediante alteraçõesprevistas no projeto de reforma do Estado. A EC 15 afetou diretamente a autonomiamunicipal ao instituir limites à criação de novos municípios, tratando como oportunistas todosos processos de emancipação municipal deslanchados ainda antes da entrada em vigor daConstituição de 1988. Durante o governo Lula, foram editadas duas novas emendas: a 57, nosentido de convalidar os municípios criados até o fim do ano de 2006 (cuja instalação estavasendo questionada depois de vigorar a EC 15), e a EC 58, estabelecendo o número máximo devereadores segundo o porte populacional dosmunicípios, o que poderá aumentar o número devereadores, ainda que tenha sidomantido o teto das despesas com a Câmara de Vereadores.

A maior parte dos novos municípios, assim como a maior parte daqueles já 
existentes, tem sua receita municipal muito dependente das receitas de transferências, emparticular do Fundo de Participação dos Municípios (FPM). Este é constituído de $23,5 \%$ dosomatório dos impostos sobre produtos industrializados e sobre a renda. O critério dedistribuição do $\mathrm{FPM}^{6}$ é diretamente proporcional à população municipal e inversamenteproporcional à sua renda per capita.

Trata-se de uma fonte de receita municipal com viés redistributivista quefavorece os municípios de pequeno porte localizados em regiões menos dinâmicas. Nessascondições, e sem que tenha havido aumento da arrecadação dos impostos que compõem oFPM, o aumento no número de municípios produz perda de receita dos já instalados. Osmunicípios recém-emancipados, por outro lado, garantem uma receita que, antes daemancipação, era alocada sistematicamente na sede do município ao qual o distrito pertencia.

A criação dos aproximadamente 1.500 municípios nas últimas duas décadas levou ao aumento dos gastos relacionados à instalação dos poderes Executivo e Legislativonesses novos municípios. Cabe lembrar, todavia, que, embora ineficiente, essa foi umamaneira de redistribuir recursos para localidades não beneficiadas pelos investimentospúblicos municipais antes da emancipação dos distritos. O aumento da capilaridade da redeurbana, por sua vez, ampliou a acessibilidade aos serviços sociais e à Justiça. Ademais, háevidência de que a emancipação de antigos distritos à condição de novos municípios teria sidoinstrumento de melhoria nos indicadores de condições de vida em localidades antes muitoisoladas, situadas em municípios territorialmente grandes, como é o caso de vários dos novosmunicípios criados na Região Norte (STEINBERG; MANIÇOBA, 2006).

Podemos concluir afirmando que as alterações constitucionais realizadassugerem forte preocupação em controlar gastos públicos, o que é muito justificável em contexto de forte crise fiscal, experimentado no País ao longo da década de 1990. Mas a evidência empírica indica que os municípios não têm muita responsabilidade pelodéficitpúblico; ao contrário, têm contribuído para mitigá-lo, além do que têm

\footnotetext{
${ }^{6}$ Segundo a Lei Complementar 63/89, o FPM será assim distribuído entre os municípios: 10\% entre as capitaisestaduais, $3,6 \%$ entre os municípios com mais de 156.216 habitantes e os $86,4 \%$ restantes entre os demaismunicípios, aí incluídos aqueles com população superior a 156.216 habitantes.
} 
aumentado suaarrecadação própria (STN, 2008). A justificativa para essecomportamento mais responsivoseria ter maior autonomia financeira para realizar investimentos públicos. A seção a seguirapresenta alguns dados que permitem situar o desempenho das finanças públicas municipais, de modo a ilustrar como as alterações legais impactam a autonomia financeira dosmunicípios.

\section{Recentralização e autonomia municipal: algumas evidências}

A conquista de maior autonomia financeira pelos municípios a partir da Constituição Federal de 1988 não pode ser igualmente experimentada por todos os municípiosbrasileiros, mas apenas por um grupo com maior expressão populacional, conforme sedepreende na Tabela 1. Nela, os municípios brasileiros estão divididos por classes detamanho. Os indicadores selecionados são relativos à participação dos três principais itens dasreceitas municipais, além do percentual dos investimentos nas despesas orçamentárias.

Os indicadores de receita são: a) participação das receitas tributárias nasreceitas orçamentárias; b) participação das receitas do FPM (Fundo de Participação dosMunicípios) nas receitas orçamentárias; e c) participação das receitas do ICMS(Imposto deCirculação de Mercadorias) nas receitas orçamentárias. O primeiro refere-se à capacidade domunicípio de arrecadar impostos de sua própria competência tributária, enquanto os outrosdois referem-se a transferências dos governos federal e estadual, respectivamente.Cabe, no entanto, observar que o critério de distribuição dessas duas fontes dereceitas de transferências é muito distinto: o FPM tem um viés redistributivista e o ICMS não;este último é distribuído segundo, basicamente, a participação do município na arrecadaçãodesse imposto estadual, o que lhe confere a condição de uma "quase receita própria". Assim, émuito diferente a situação de município que seja mais dependente do FPM e do ICMS:quando a maior é dependência do primeiro, maior é a fragilidade na economia municipal,ocorrendo o contrário com o segundo. A participação dos investimentos nas despesasorçamentárias foi utilizada para avaliar se uma possível maior autonomia financeira está setraduzindo em maiores investimentos próprios municipais, o que foi considerado umindicador de êxito da descentralização e da autonomia municipal. 
Tabela 1: Estrutura das receitas municipais e participação dos investimentos nas despesas municipais no Brasil no ano de 2010, em\%

\begin{tabular}{|l|l|l|l|l|}
\hline $\begin{array}{l}\text { Classes de } \\
\text { tamanho/Indicadores }\end{array}$ & $\begin{array}{l}\text { Receitas } \\
\text { tributárias }\end{array}$ & FPM & ICMS & Investimentos \\
\hline $0-30$ mil (4.192) & 6,45 & 35,16 & 19,97 & 13,03 \\
\hline $30-50$ mil (440) & 10,92 & 23,46 & 20,74 & 11,28 \\
\hline $50-100$ mil (309) & 12,60 & 18,82 & 21,72 & 10,08 \\
\hline $100-300$ mil (194) & 18,44 & 12,60 & 23,49 & 11,43 \\
\hline $300-500$ mil (40) & 22,94 & 8,37 & 22,87 & 11,85 \\
\hline $500-1.000$ mil (23) & 22,56 & 7,44 & 23,52 & 9,18 \\
\hline+ de 1.000 mil (14) & 35,85 & 3,95 & 16,69 & 8,57 \\
\hline
\end{tabular}

Fonte: Elaboração própria a partir de dados da Secretaria do Tesouro Nacional, FINBRA,2010. Naquele ano, havia dados disponíveis para 5.212 municípios. Os números entreparênteses referem-se ao número de municípios segundo as classes de tamanho de suapopulação.

A análise dos indicadores revela que: a) as receitas tributárias tendem a se elevar na razão direta do crescimento das classes de tamanho populacional das cidades; b) queo FPM, ao contrário, tende a diminuir com a progressão das classes de tamanho populacional;c) que o ICMS constitui a principal fonte de receita dos municípios de médio porte; d) que osinvestimentos são maiores nas cidades menores do que nas maiores, sugerindo falta de relaçãoentre maior autonomia financeira e alocação de gastos com investimentos; e) que as cidadescom população inferior a 50 mil habitantes têm no FPM seu principal componente dasreceitas orçamentárias; e f) que as cidades com população superior a 100 mil habitantes têmno ICMS, principalmente, e nas receitas tributárias, secundariamente, suas principais fontesde receitas orçamentárias.

Esses resultados apontam para uma associação entre maior autonomiamunicipal e tamanho da população. São os municípios de maior porte populacional quepodem experimentar a descentralização como uma inovação que lhes permita serprotagonistas das políticas públicas. As cidades de pequeno porte, ao contrário, dependem dasreceitas de transferências redistributivistas (FPM), o que limita sua experiência dedescentralização à condição apenas de membros de redes federativas, mas não como 
formuladores e financiadores de políticas próprias, de interesse local.

A rede urbana brasileira atual é constituída de 5.565 municípios,aproximadamente $70 \%$ dos quais têm população inferior a 20 mil habitantes. Apesar de seuexpressivo número e da sua importância como instrumento de redistribuição espacial dedireitos dos cidadãos, esses municípios são isentos da obrigatoriedade de elaborar planosdiretores com a definição de sua política urbana.

Apesar disso, não estão isentos de assumir a responsabilidade pela execução de outras políticas públicas nacionais, casos da Educação e da Saúde. Responsabilizam-se, ademais, por iniciativas de políticas que são deveres constitucionais da União e dos estados.Segundo Bremaeker (2006), os municípios com até 10 mil habitantes gastam, em média, $10,85 \%$ de suas receitas com a manutenção de serviços que deveriam ser sustentados poroutras esferas de governo, percentual muito mais elevado do que a média de gastos de todosos municípios brasileiros, da ordem de 4,46\% das receitas municipais totais. Essatransferência de responsabilidade não é assumidavoluntariamente; ocorre por pressão dosresidentes que não podem prescindir, por exemplo, da presença e conservação do prédio dofórum municipal, enquanto o governo estadual contingencia (ou nem executa) o repasse dosrecursos necessários para tal finalidade.

A forte dependência das receitas de transferência, principalmente do Fundo deParticipação dos Municípios, decorre da limitada capacidade contributiva da população dosmunicípios de pequeno porte. Quanto menor o município, menor tende a ser a renda média desua população, como o IBGE identificou na pesquisa Indicadores Sociais Municipais,elaborada com base nos dados do Censo de 2000. Segundo essa fonte, o valor do rendimentomédio dos responsáveis pelos domicílios particulares permanentes dos residentes emmunicípios com até 5.000 habitantes era o equivalente a $\mathrm{R} \$ 424,08$, valor que seguia semprecrescendo até atingir $\mathrm{R} \$ 1.190,00$ entre os residentes nos municípios com população superiora 500 mil habitantes (SANTOS, 2010).

Não causa surpresa, portanto, que os fluxos migratórios internos continuemocorrendo, sempre originários de regiões deprimidas para as mais desenvolvidas, de cidadesde pequeno porte em direção às maiores; verifica-se que as cidades médias se tornaram osprincipais destinos dos migrantes, enquanto os 
municípios com população inferior a 10 milhabitantes têm perdido população entre 2000 e 2010 (IBGE, 2011).

Nessas condições,diminuir a importância relativa das transferências constitucionais (o FPM, sobretudo) éasfixiar os governos da grande maioria dos municípios e alimentar seu esvaziamentoeconômico, com consequente perda de população. Isso, por sua vez, torna mais graves osproblemas de insustentabilidade socioambiental nas grandes cidades.

Muito melhor é a situação dos municípios que contam com população superior a 100 mil habitantes - apenas 5\% do universo municipal brasileiro. Estes são os que sofremmaior pressão demográfica, apresentando maior taxa de crescimento populacional que osdemais, o que os torna particularmente sensíveis à necessidade de melhorar sua arrecadaçãoprópria, além de investir na sua capacidade administrativa.

Esses municípios têm uma baseeconômica urbana que lhes permite desfrutar de maior autonomia financeira, em função domaior percentual de sua arrecadação tributária em relação às receitas municipais.Essa concentração das receitas nos municípios de maior porte fica evidente tambémem estudo da Secretaria do Tesouro Nacional (2008) traçando um perfil da evolução dasfinanças municipais entre 1998 e 2007, conforme se observa na Tabela 2.

Tabela 2: Distribuição da população e da receita bruta segundo grupos de municípios

\begin{tabular}{|l|l|l|l|}
\hline Faixas de população & População (2000) & PIB (2000) & $\begin{array}{l}\text { Receita bruta } \\
\text { média } \\
(\mathbf{1 9 9 8 / 2 0 0 7 )}\end{array}$ \\
\hline Pop > 1.000.000 & $24,5 \%$ & $32,6 \%$ & $30,4 \%$ \\
\hline $1.000 .000>$ Pop $>300.000$ & $16,9 \%$ & $17,6 \%$ & $15,6 \%$ \\
\hline $300.000>$ Pop $>50.000$ & $28,6 \%$ & $29,4 \%$ & $26,8 \%$ \\
\hline Pop < 50.000 & $30,0 \%$ & $20,5 \%$ & $27,2 \%$ \\
\hline
\end{tabular}

Fonte: STN (2008) - Perfil e evolução das finanças municipais 1998/2007.

É possível observar a forte concentração da população nos maiores municípios brasileiros. Mas é ainda maior o peso destes municípios no PIB e nas receitas municipais. O estudo indica ainda que, afora poucas exceções (a exemplo deFPM, de 
transferências de capital, de outras transferências para as quais o Grupo 4detémparticipação relevante), importantes elementos da receita, da despesa, do ativo e do passivodos municípios brasileiros estão concentrados nos municípios compopulação superior a 1milhão de habitantes. Dentro de um universo de 5.564 municípios brasileiros, aqueles 12 que no ano 2000 tinhampopulação superior a 1 milhão de habitantes foram responsáveis por mais de $90 \%$ do estoqueda dívida externa e $80 \%$ do estoque da dívida interna. É preciso admitir,portanto, que osmunicípios não estão endividados, salvo um pequeno número de grandes cidades. Não é justo,assim, associar descentralização das estruturas governamentais com descontrole das finançaspúblicas.

Ao atualizarmos para o ano 2010 as informações sobre finanças públicas do grupo de municípios com mais de 100 mil habitantes (subiu de 12 para 14, segundo o Censo Demográfico de 2010) encontramos dados que merecem ser destacados. Naquele ano, o peso destes 14 municípios no conjunto dos municípios brasileiros correspondia a:

- $\quad 26 \%$ das receitas orçamentárias;

- $\quad 47 \%$ das receitas tributárias;

- $51 \%$ da arrecadação do IPTU;

- $50 \%$ da arrecadação do ISS;

- $46 \%$ da arrecadação do ITBI;

- $21 \%$ da quota-parte do ICMS;

- $6 \%$ do FPM;

- $21 \%$ dos investimentos.

Esse pequeno grupo de municípios foi responsável por metade da arrecadação dos dois principais tributos de competência municipal (ISS e IPTU). Os dois tributos incidentes sobre a propriedade imobiliária (IPTU e ITBI) também têm sua arrecadação fortemente concentrada nesses 14 municípios, o que sugere que o uso extrafiscal para fins de política de controle do uso do solo esteja disponível apenas para estes grandes municípios.

Não obstante sua autonomia financeira, o peso destes municípios nas receitas orçamentárias e nas despesas de investimentos correspondem a $26 \%$ e $21 \%$, respectivamente. Esse resultado sugere o impacto redistributivo das transferências intergovernamentais nas receitas municipais brasileiras, particularmente do FPM. 
A grande maioria dos municípios não conta com dinamismo econômicoque lhes permita arrecadar tributos com peso nas receitas municipais. São municípios quedependem de transferências intergovernamentais, conforme a evidência encontrada noreferido estudo da Secretaria do Tesouro Nacional (2008). Entre elas, as transferências quemais avançaram como proporção das receitas municipais foram as oriundas do SUS,FUNDEF (que passaria a ser o FUNDEB) e o FNDE. Ao longo do período 1998/2007, elaspassaram de 10,1\% da receita bruta dos municípios com menos de 50 mil habitantes para17,7\%, em 2007.

Analisando alguns itens das despesas municipais, as informações disponíveis sugerem que não há relação entre aumento das receitas e avanço nos investimentos. Segundoo já referido estudo do STN (2008), ao longo do período considerado os investimentospúblicos municipais giraram em torno dos $10 \%$ em relação às receitas brutas municipais.

Essa mesma falta de associação entre receitas e investimentos já havia sido identificada em estudo de SANTOS (2008) sobre finanças públicas dos municípios com população superior a 100 mil habitantes. Naquele estudo, o objetivo era avaliar a autonomiafinanceira dos municípios ao longo do período correspondente aos dois mandatos dopresidente Fernando Henrique Cardoso (1995/1998 e 1999/2002). Nesse período, houve umprocesso de recentralização das receitas públicas em favor da União, por meio da criação decontribuições sociais e financeiras, que são tributos nãopartilháveis com os estados emunicípios. Tal concentração de recursos, no entanto, foi acompanhada da elevação dastransferências voluntárias, especialmente entre os municípios que aumentaram seusinvestimentos, fazendo supor que a perda relativa de autonomia financeira foi compensadacom transferências negociadas caso a caso. Nunca é demais lembrar que essa situação nãocondiz com a desejada autonomia financeira, que permitiria que os municípios definissem aalocação dos seus gastos, incluídos aí os investimentos.

Outro estudo de SANTOS (2012) avaliando a autonomia financeira dos municípios brasileiros na primeira década do século XXI encontrou evidencias de que as receitas de transferências de capital seguem sendo utilizadas para mitigar disparidades entre os municípios. Esta foi uma fonte de receita que representou 3,18\% das receitas orçamentárias da média dos municípios brasileiros em 2010, resultado 
superior ao observado para o grupo de municípios (283) com população superior a 100 mil habitantes, da ordem de $1,97 \%$. Cabe ainda acrescentar que os montantes desta fonte de financiamento municipal foi maior nos anos de eleições municipais (2000, 2004 e 2008), declinando no ano seguinte (primeiro ano de mandado do prefeito eleito), sugerindo o uso político das transferências de capital.

Não é possível afirmar, entretanto, quais são os municípios que mais se beneficiamde tais transferências negociadas nem se são municípios que experimentaram maior ou menoresforço de arrecadação própria. Cabe reconhecer, todavia, que essas transferências seguemsendo utilizadas e afetam negativamente a formação de uma desejada rede federativa baseadaem cooperação.

Mas há elevação de transferências ditas voluntárias de natureza não discricionáriaque representaram verdadeiras "minirreformas tributárias", segundo a visão de José RobertoAffonso (2004). Este é o caso da criação de dois fundos: o FUNDEF (transformado emFUNDEB pela Emenda 53) e o SUS. Sem desrespeitar a autonomia formal dos municípios, aUnião formulou políticas de Educação e Saúde para as quais logrou a adesão desses entesfederativos para sua execução, por meio do acesso às transferências dos dois mencionadosfundos, mas tornando obrigatória uma contrapartida financeira deles.

Tal medida refletiu-se no aumento da participação dos municípios nos gastos sociaisdo poder público. Se, de um lado, há um reflexo negativo em relação à autonomia alocativadas receitas municipais, por outro, trata-se de políticas que garantem grande capilaridade noacesso aos serviços que foram considerados direitos sociais dos cidadãos brasileiros.

Essas minirreformas foram introduzidas no governo FHC, mas foram mantidas nogoverno Lula, que inclusive aumentou o alcance de uma, transformando em FUNDEB oantigo FUNDEF. Na mesma direção, pode-se citar a Política Habitacional de Interesse Social(Lei $n^{\circ} 11.124$, de 16 de junho de 2005), estruturada para operar como rede federativavertical, o mesmo desenho institucional que prevalece no maior programa de transferênciacondicionada de renda existente no País, o Programa Bolsa Família (DRAIBE, 2009). Devemser mencionadas, ainda, a criação de outras políticas, que incluíam estímulo aoconsorciamento municipal, casos da Política Nacional de 
Saneamento Básico (Lei n 11.445,de 05 de janeiro de 2007) e da Política de Resíduos Sólidos (Lei $\mathrm{n}^{\mathrm{o}}$ 12.305, de 02 de agosto de2010).

\section{Conclusões: aperfeiçoando o federalismo brasileiro...}

Desde a década de 1980 tem havido um generalizado processo detransferência de responsabilidade de políticas públicas até as esferas locais de governo. Esseprocesso não se restringe às estruturas federativas, mas também abrange estados unitários.

A experiência internacional, no entanto, sugere que não existe uma única fórmula deorganização do território para administrar aquelas políticas, variando muito as práticas,desde simples processos de desconcentração administrativa até experiências dedescentralização, com maior autonomia política dos governos locais (VASCO, 2007). Ofederalismo brasileiro, da forma como emergiu na Constituição de 1988, optou por essaversão de descentralização política.

A elevação do Município à condição de ente federativo no Brasil teve doiselementos constitutivos: internamente, foi parte do processo de redemocratização das

estruturas de poder após 21 anos de regime militar; ao mesmo tempo, correspondeu à influência do debate internacional sobre as vantagens da descentralização das políticas públicas. O resultado teria sido a grande fragmentação do Estado, dificultando acoordenação entre as três esferas de governo, mas também a maior capilaridade do poderpúblico, ampliando o acesso às políticas sociais.

Essa segunda característica tem sido menos destacada do que a primeira.Afinal, é na esfera local que o clientelismo político se manifesta de forma mais clara, podendoser identificados os grupos de interesse que mais se beneficiam da ação governamental. Acentralização do poder, entretanto, não será necessariamente o instrumento que porá fim aoclientelismo político, o que ficou evidente nas experiências anteriores de governoscentralizadores experimentados no País.

A centralização política, aliás, enfrenta maiores resistências diante do avanço das estruturas democráticas de poder, ampliadas com o uso das novas tecnologias, que vêmcolocando em xeque a organização tradicional de representatividade política no mundo, oBrasil aí incluído. A queda de inúmeros regimes autoritários ao longo da primeira década donovo século é um indicador dessa crise de representatividade. Esta, 
contudo, não é umacaracterística apenas entre os regimes autoritários, mas inclui as democracias ocidentais, ondemovimentos sociais desafiam os governos a apresentar alternativas socialmente aceitáveispara o enfrentamento da crise econômica.

A crescente demanda por participação política, entretanto, não é sinônimo demunicipalização das políticas públicas, no sentido de transferir para os governos locais

(municipais, no caso brasileiro) toda a responsabilidade por sua formulação, financiamento eexecução. Mas parece ter sido este o entendimento que prevaleceu logo após a entrada emvigor da atual Constituição brasileira, quando o Município tornou-se ente federativo.

Os constituintes de 1988 incluíram na Carta Maior artigos prevendocomportamento mais cooperativo entre os entes federativos. Deixaram, todavia, que a

legislação ordinária regulasse tal cooperação. $\mathrm{Na}$ ausência de lei, os entes passaram a apresentar comportamento muito mais competitivo do que colaborativo. A disputa federativa, conjugada com a falta de eficácia nas políticas públicas, levou a uma crítica emrelação à autonomia municipal, que recebeu a maior parcela na responsabilidade por aquelemau resultado nos primeiros anos pós-Constituição.

Num segundo momento, durante o período 1995/2002, o presidente Fernando Henrique Cardoso logrou atingir a estabilização monetária, após quase duas décadas de descontrole inflacionário. A defesa da estabilização, conjugada à crise internacional de 1997/1998, levou sua administração a ter seu foco no ajuste fiscal, o que resultou no ataque àautonomia dos municípios.

Desde o processo de descentralização instituído pela atual Constituição, aUnião vem lutando para reaver os recursos que se viu obrigada a transferir aos estados emunicípios. O debate a propósito da incapacidade financeira e técnica de os Municípios

assumirem maior protagonismo nas políticas públicas produziu dois tipos de resultados: oprimeiro foi a recomposição da participação da União na arrecadação fiscal, por meio doaumento das contribuições (recursos não partilháveis com outras esferas de governo); osegundo resultado foi a criação de instrumentos legais para controle dos gastos públicos,como foi o caso da Lei de Responsabilidade Fiscal. Isso denota grande 
preocupação com aresponsabilização em relação às finanças públicas, mas não com a eficiência das políticas.

Esse é o diagnóstico que prevaleceu durante os dois mandatos da Presidência FernandoHenrique Cardoso, quando a crise fiscal levou ao maior controle dos gastos públicos.

A possibilidade de que o pacto federativo seja mantido com políticas públicasmais eficientes depende de que sejam logrados avanços na maior cooperação federativa.

Ainda durante o governo Cardoso foram realizados avanços no desenho institucional daspolíticas, como exemplificam as de Educação e Saúde. Mas, foi nos oito anos do governoLula que a "coordenação federativa" mais avançou, tendo sido introduzidos novos critérios deredistribuição das transferências intergovernamentais, associados a alguma condição queconduzisse à maior efetividade das políticas sociais.

A coordenação em redes federativas verticais parece ser mais simples, uma vez que o governo federal pode oferecer benefícios pecuniários aos municípios que aceitem fazerparte de um arranjo federativo para implementar uma política. Esse é o caso do desenho dapolítica de financiamento da Saúde, na qual alguns municípios são considerados polosregionais por aceitarem atender a população residente em municípios vizinhos.

A coordenação em redes federativas horizontais é mais complexa, pordepender de acordos voluntários estabelecidos entre entes da mesma esfera de governo. Taisacordos são necessários para viabilizar pactos de governança que viabilizem a oferta deserviços públicos. Novos recortes territoriais estão fazendo emergir não apenas mais regiõesmetropolitanas, mas também consórcios intermunicipais em torno de objetivos específicos depolíticas públicas cujo alcance ultrapassa as fronteiras municipais (principalmente entreaqueles municípios de pequeno porte, que são a grande maioria dos municípios brasileiros).

Em abril de 2005 entrou em vigor a Lei $\mathrm{n}^{\circ}$ 11.107, instituindo os consórcios intermunicipais como figuras de direito público, o que vem incrementando ainda mais o associativismo municipal voluntário, já bastante disseminado nos setores de saúde e meioambiente. O Decreto 6.017, de 17/01/2007, que a regulamentou, estimula a formação deconsórcios públicos. Em seu artigo 37, orienta os órgãos e entidades 
federais no sentido dedarem preferência às transferências voluntárias para Estados e Municípios cujas ações sedesenvolvam por meio de consórcios públicos.

Além da União, alguns estados, como o do Rio de Janeiro, também editaram leis estimulando a formação de consórcios intermunicipais, caso da Lei Estadual 5.576, de 13/11/2009.

Cabe destacar que o crescimento dessas formas de associativismo municipal émais visível entre os municípios localizados nas Regiões Sudeste e Sul, enquanto nas demaisainda é incipiente (SANTOS, 2008; VASCO, 2007).

Há, portanto, formas distintas de experiências de autonomia municipal no país: nas Regiões Sudeste e Sul (e nos seus municípios de médio e grande porte), ela se manifestapor meio do protagonismo dos atores locais, interessados em comandar o processo deformulação de políticas em face das demandas territoriais locais. Nas demais regiões, a"municipalização" das políticas deve ser considerada uma estratégia de distribuir serviços quese tornaram direitos sociais, fazendo parte do padrão mínimo de direitos de cidadania (comosaúde, educação e moradia).

A autonomia municipal no Brasil vem, assim, sofrendo modificações em relação ao que foi pactuado na Constituição de 1988. Isso não resultou em perda da autonomia política do Município, que seguiu sendo “ente federativo". Mas aqueles com maiorautonomia financeira e técnica seguem sendo os grandes beneficiários do fortalecimentoinstitucional do Município no quadro federativo do País, enquanto, para a grande maioria, a"coordenação federativa" desde o governo federal é a estratégia para que participem comoatores das políticas públicas.

Esta evolução pode ser entendida como avanço institucional? Certamente que algum avanço houve, incluindo maior coordenação vertical e horizontal dos entes, sem quetenha sido ferido o pacto federativo estabelecido em 1988. Todavia, ainda prevalece grandecompetição pelas receitas de transferências de capital, utilizadas como moedas de troca asustentar um sistema político que parece estar se esgotando. Talvez por esse motivo, ainda háquem defenda a volta do antigo sistema federativo baseado em apenas dois entes, os Estados ea União. Isso, entretanto, não pode ser feito, pois a estrutura federativa tripartite é consideradacláusula pétrea pela Constituição de 1988. Diminuir o status político do Município somentepoderá ser feito por meio da elaboração de uma nova Constituição, o que na vigência doregime democrático não parece estar no 
horizonte político brasileiro. É neste contexto que sesituam as muitas reformas constitucionais discutido neste artigo. Mas, mesmo essas, nunca édemais lembrar, dependem de condições políticas muito favoráveis para serem aprovadas, pordependerem de votação na Câmara e no Senado por maioria de dois terços dos parlamentares,em duas votações.

\section{Referências bibliográficas}

AFFONSO, J. Roberto. Brasil, Um Caso À Parte. XVI Regional Seminar of Fiscal Policy. CEPAL/ILPES, Santiago do Chile, janeiro, 2004. Disponível em:www.federativo.gov.br. Consulta em 15/5/2005

ARRETCHE, Marta. Estado federativo e políticas sociais. Rio de Janeiro: Revan, 2000.

BREMAEKER, François. Pacto Federativo: Um Futuro Para os Municípios. Rio de Janeiro, IBAM, abril de 2006. Série Estudos Especiais nº 153.

DRAIBE, S. Programas de Transferências Condicionadas de Renda. In:

CARDOSO, F. H.; FOXLEY, A. (orgs.). América Latina: Desafios da Democracia e do Desenvolvimento. Políticas Sociais para além da crise. Rio de Janeiro: Elsevier, 2009. FLEURY, S. (org.). Democracia, descentralização e desenvolvimento: Brasil \& Espanha. Rio de Janeiro: FGV, 2006.

HOFMEISTER, Wilhelm; CARNEIRO, José Mário Brasiliense (org.). Federalismo na Alemanha e no Brasil. São Paulo: Fundação Konrad Adenauer, 2001. Série Debates, v. I,n ${ }^{\circ} 22$, abril.

MENDES, Marcos. Reforma constitucional, descentralização fiscal e rentseeking behaviour: o caso dos municípios brasileiros. São Paulo: Instituto Fernand Braudel de Economia Mundial, associado à Fundação Armando Álvares Penteado, 2004. Disponível em:www.braudel.org.br. Consulta em 15/5/2005

\section{SECRETARIA DO TESOURO NACIONAL. Perfil e evolução das finanças}

municipais (1998-2007). Brasília: STN, 2008.

RESENDE, F. (coord.). Desafios do federalismo fiscal. Rio de Janeiro: FGV, 2006.

SANTOS, Angela M. S. Penalva. Município, Descentralização e Território. Rio de Janeiro: Forense, 2008. 
SANTOS, Angela M. S. Penalva. Autonomia Municipal no Contexto Federativo Brasileiro. Revista Paranaense de Desenvolvimento, Curitiba, n. 120, p. 209-230, jan/jun. 2011.

SANTOS, Angela M. S. Penalva. Finanças Públicas: Uma análise da autonomia financeira dos municípios brasileiros na primeira década do século XXI.Sintese: Revista do Tribunal de Contas do Estado do Rio de Janeiro. N. 1 (jan/jun 2012) Rio de Janeiro: O Tribunal, 2006, semestral.

STEINBERG, M.; MANIÇOBA, R. S. Efeitos da centralização e descentralização no processo brasileiro de municipalização: o caso da Região Norte. Revista Economia,Sociedad y Território. El Colégio Mexiquense, vol. V. nº 20, enero/abr. 2006. VASCO, J.A.C. Formas especiais de organização do território na federação brasileira. 2007. 415 p. Dissertação (Mestrado em Direito) Programa de PósGraduação emDireito, Universidade do Estado do Rio de Janeiro. Rio de Janeiro, agosto de 2007.

\section{Anexo:}

\section{Emendas à Constituição Federal que interferem na autonomia municipal}

Emenda 3, de 17/03/1993. Reforma o sistema tributário nacional, criando o Imposto Provisóriosobre Movimentação Financeira (IPMF); eliminação do Imposto sobre Vendas a Varejo de Combustíveis Líquidos e Gasosos (IVV), decompetência dos municípios.

Emenda de Revisão 1, de 01/03/94. Institui o Fundo Social de Emergência.

Emenda 10, de 04/03/1996. Prorroga por dois anos o Fundo Social de Emergência, rebatizando-o deFundo de Estabilização Fiscal.

Emenda 12, de 15/08/1996. Institui a cobrança da Contribuição Provisória sobre MovimentaçãoFinanceira (CPMF), com arrecadação integralmente destinada à Saúde.

Emenda 14, de 12/09/1996. Institui o Fundo de Desenvolvimento do Ensino Fundamental(FUNDEF).

Emenda 15, de 12/09/1996. Institui limites à criação de novos municípios.

Emenda 17, de 22/12/1997. Prorroga o Fundo de Estabilização Fiscal por dois anos. 
Emenda 19, de 04/06/1998. Institui reforma administrativa que inclui princípios e normas para ocontrole das despesas e finanças públicas e custeio dos três âmbitos degoverno.

Emenda 21, de 18/03/1999. Prorroga a CPMF por três anos, com aumento da alíquota.

Emenda 25, de 14/02/2000. Limita as despesas com o Poder Legislativo municipal.

Emenda 26, de 14/02/2000. Transforma a moradia num direito social cuja responsabilidade écompartilhada pelos três âmbitos de governo.

Emenda 27, de 21/03/2000. Institui a Desvinculação de Receitas da União (DRU).

Emenda 29, de 13/9/2000. Altera a redação dos artigos 34, 35, 156, 160, 167 e 198 da

CF e acrescenta artigo ao Ato das Disposições Transitórias para assegurar os recursos mínimos para o financiamento das ações e serviços públicos de Saúde.

Emenda 31, de 14/02/2000. Institui o Fundo de Combate e Erradicação à Pobreza, com responsabilidade compartilhada entre os três âmbitos de governo.

Emenda 33, de 11/12/2001. Altera o sistema tributário nacional, ao criar a Contribuição deIntervenção no Domínio Econômico, incidente sobre combustíveis(CIDE).

Emenda 37, de 12/06/2002. Altera o sistema tributário nacional; prorroga a CPMF até 31/12/2004,modifica alíquotas e redistribui os recursos da CPMF para a Previdência

Social, a Saúde e o Fundo de Combate à Pobreza; estabelece alíquotamínima do ISS, prevê lei complementar para alterar o ISS (no sentidode coibir a guerra fiscal entre os municípios, amplia a base de cálculodo ISS, incluindo muitos novos serviços, define alguns serviços que nãodeverão mais pagar o imposto no local da sede e sim onde são prestados).

Emenda 39, de 19/12/2002. Altera o sistema tributário nacional ao criar a contribuição para ocusteio da iluminação pública nos municípios e no Distrito Federal.

Emenda 42, de 15/4/2004. Altera o sistema tributário nacional ao permitir que os municípiospossam ficar com toda a arrecadação do ITR, desde que o fiscalize; ao transferir 25\% da CIDE para os estados, devendo estes transferir 25\%para os municípios.

Emenda 44, de 30/6/2004. Altera o sistema tributário nacional ao alterar o percentual da CIDE quedeve ser partilhado com as esferas infranacionais, passando a ser de $29 \%$ da arrecadação. 
Emenda 53, de 19/12/2006. Altera o funcionamento do FUNDEF, ampliando para incluir toda aEducação Básica, e criando o FUNDEB.

Emenda 55, de 20/9/2007. Altera o sistema tributário para aumentar em 1\% o FPM.

Emenda 56, de 20/12/2007. Prorroga o prazo das DRU.

Emenda 57, de 18/12/2008. Convalida os atos de criação, fusão, incorporação e desmembramentode municípios cuja lei tenha sido publicada até 31/12/2006.

Emenda 58, de 23/9/2009. Altera a composição das câmaras municipais, possibilitando aumentar onúmero de vereadores, ainda que o teto para despesa com as câmaras tenha sido mantido.

Emenda 59, de 11/11/2009. Reduz anualmente o percentual da DRU incidente sobre os recursos doFUNDEB; prevê a obrigatoriedade de quatro a dezessete anos de ensino e amplia a abrangência dos programas suplementares para todas asetapas da Educação Básica.

Emenda 64, de 4/2/2010. Acrescenta o direito à alimentação no rol dos direitos sociais, comoresponsabilidade das três esferas de governo.

Emenda 67, de 22/12/2010. Prorroga, por tempo indeterminado, o prazo de vigência do Fundo deCombate e Erradicação à Pobreza.

Artigo encaminhado para publicação em novembro de 2012.

Artigo aceito para publicação em dezembro de 2012. 